\title{
Agroclimatic conditions in China under climate change scenarios projected from regional climate models
}

\author{
Zhan Tian, ${ }^{\text {a }}$ Xuchao Yang, ${ }^{\text {b,c* } * \text { Laixiang Sun, }, \text { e,f }}$ Günther Fischer, ${ }^{\mathrm{e}}$ Zhuoran Liang ${ }^{\mathrm{a}}$ and Jie Pan ${ }^{\mathrm{g}}$ \\ a Shanghai Climate Center, Shanghai, China \\ ${ }^{\mathrm{b}}$ Ocean College, Zhejiang University, Hangzhou, China \\ ${ }^{\mathrm{c}}$ Zhejiang Institute of Meteorological Sciences, Hangzhou, China \\ ${ }^{\mathrm{d}}$ School of Oriental \& African Studies, University of London, UK \\ ${ }^{\mathrm{e}}$ International Institute for Applied Systems Analysis (IIASA), Laxenburg, Austria \\ ${ }^{\mathrm{f}}$ Department of Geographical Sciences, University of Maryland, College Park, USA \\ ${ }^{\mathrm{g}}$ Institute of Environment and Sustainable Development in Agriculture, Chinese Academy of Agricultural Sciences, Beijing, China
}

\begin{abstract}
The recent warming trends have led to rising concerns on how the changing climate has been altering and will continue to alter agroclimatic conditions in China. In this study, high resolution climate scenarios from regional climate models (RCMs) are used as input to the agro-ecological zones (AEZ) model for China and to compute a comprehensive set of agroclimatic indicators. Uncertainties in the projected impacts of climate change on agroclimatic conditions are also discussed with respect to (1) RCM outputs for different emission scenarios, and (2) differences in projections obtained from two different RCMs under the same emission scenario. The results indicate a significant extension of the crop growing period in tandem with the rising temperatures during the crop growing season, which may lead to increase in multi-cropping opportunities at high latitudes and thus advance the total potential output per unit of cropland. However, the results show that the Southwest China will experience a significant reduction in the value of humidity index, implying severe challenges for future agricultural development in the region. Spatially explicit patterns of changes in future agroclimatic conditions, as revealed in this study, can be beneficial for policy-makers, farming communities and other stakeholders to assess risk factors, design adaptation and mitigation measures, and improve management practices at the local to regional scales.
\end{abstract}

KEY WORDS agroclimatic conditions; regional climate model; AEZ model; climate change

Received 27 December 2012; Revised 3 August 2013; Accepted 14 November 2013

\section{Introduction}

According to the Fourth Report of the Intergovernmental Panel on Climate Change (IPCC), the global average temperature increased by $0.74{ }^{\circ} \mathrm{C}$ from 1906 to 2005 . This warming trend is likely to continue and the global average temperature will rise between 1.8 and $4.0^{\circ} \mathrm{C}$ in the 21st century (Solomon et al., 2007). The observed warming in China was much higher than the global average and also higher than the average of the Northern Hemisphere. Annual mean surface temperature in China as a whole rose by about $1.3^{\circ} \mathrm{C}$ from 1951 to 2004 (with a warming rate of about $0.25^{\circ} \mathrm{C} / 10 \mathrm{a}$ ) and the warming has accelerated since the mid-1980s (Ren et al., 2005). Climate is one of the most important limiting factors for agricultural production (Moonen et al., 2002). Climate change is expected to exert significant impact on both regional and global food production through changes in overall agroclimatic conditions, including temperature regimes and precipitation which affect crops suitability and soil moisture conditions (Fischer et al., 2005). Along

\footnotetext{
* Correspondence to: X. Yang, Ocean College, Zhejiang University, 866 Yuhangtang Road, Xihu District, Hangzhou 310058, P. R. China. E-mail: yangxuchao@gmail.com
}

with the recent warming trends there are rising concerns on how the changing climate has been altering and will continue to alter agroclimatic conditions in China and thereby affect crop production in the future. It has been acknowledged that regional warming in past 50 years has extended the length of the potential growing season for crops and allowed northword expansion of the northern limits of cropping systems (Piao et al., 2006; Yang et al., 2010). Meanwhile, the number of frost days have shown a declining trend across most cropland regions (Zhai and Pan 2003; Qian and Lin 2004). Piao et al. (2010) present a comprehensive review of the recent literature on this important topic.

Many agricultural activities, including the selection of cultivars and crop rotation schemes as well as the timing choices of field management operations, etc., have long been based on empirically tested agroclimatic zoning schemes and/or agroclimatic indices that are both practical and understandable to the agricultural users. To better understand and manage the risks posed by climate change it is helpful to employ a set of agroclimatic parameters that are capable of indicating the consequences of climate change for crop production. In this study, we employ such key agroclimatic parameters as temperature sums and length of temperature growing periods; the reference 
and actual evapotranspiration and humidity index; and the length of growing period to provide a general picture of future agroclimatic conditions at the grid-cell level for China.

Climate change scenarios for impacts assessment are basically generated by General Circulation Models (GCMs). The horizontal resolution of most present-day GCMs is at the order of a few hundred kilometres (Meehl et al., 2007). Therefore, they are incapable of capturing significant subgrid scale features such as complex topography and land surface characteristics. Bridging the gap between the resolution of GCMs and regional and local scale processes represents a great challenge for the impact assessment of climate change, including the application of climate change scenarios to agricultural models. To meet the challenge, considerable efforts have been devoted to the development of such techniques known as 'downscaling'. Two mainstream approaches exist for the downscaling of large-scale GCM output to a finer spatial resolution. The first one is the statistical downscaling techniques which have been employed to generate meteorological data with a high spatiotemporal resolution to assess future changes in agroclimatic conditions in Europe (Trnka et al., 2011a, 2011b).

The second approach is dynamic downscaling which is associated with regional climate models (RCMs). As RCMs can much better represent the local land surface variables affecting the regional climate and internal climate variations, the application of RCMs has become increasing popular and is regarded as a powerful way of downscaling the GCM simulations of large-scale circulation patterns for obtaining climate change scenarios at a high resolution to serve the regional climate change impacts assessments (Wang et al., 2004).

It is worth noting that regional studies of future agroclimatic conditions based on high-resolution RCM projections have mainly focused on Europe (Fronzek and Carter 2007; Olesen et al., 2007; Trnka et al., 2010). For China, most of the existing studies focus on assessing historical changes of agroclimatic resources inventories for different regions of China (Dong et al., 2009; Li et al., 2010; Sun et al., 2010; Dai et al., 2011). There has been a shortage of studies assessing future changes in agroclimatic indicators posed by climate change at the pan-China scale. More specifically, to the best of our knowledge, our study is among the first to conduct a comprehensive assessment of future agroclimatic conditions based on RCM outputs for China. In this study, we utilize the best available high-resolution RCM projections of PRECIS (Providing Regional Climates for Impacts Studies) and RegCM3 for China (Xu et al., 2006; Gao et al., 2011) and comprehensively evaluate China's agroclimatic conditions under present and expected future climates, with the aim to provide understandable information of climate change impacts on agriculture to decision makers, farming communities and other stakeholders.

To partly address the uncertainty issue in the estimated impacts of climate change on agroclimatic conditions for China, we compare assessment outcomes between different $\mathrm{CO}_{2}$ emission scenarios $(\mathrm{A} 1 \mathrm{~B}, \mathrm{~A} 2, \mathrm{~B} 2$ of the IPCC Special Report on Emission Scenarios) under the same PRECIS RCM, and then between two different RCMs under the same emission scenario (A1B).

\section{Materials and methods}

\subsection{AEZ Model and agroclimatic indicators}

The modelling tool for our assessment of past and future agroclimatic conditions is the Agro-ecological Zone (AEZ) database and methodology, jointly developed by International Institute for Applied Systems Analysis (IIASA) and Food and Agricultural Organization (FAO) of the United Nations (Fischer et al., 2002). AEZ uses agronomic-based knowledge to assess agroclimatic suitability and land resources availability, examine farmlevel management options, and estimate crop production potentials. It employs detailed spatial meteorological, biophysical and socio-economic datasets to distribute its computations at fine gridded intervals over the entire territory of the jurisdiction concerned. The assessments of agroclimatic and land resources inventories is then used to evaluate, for specified management conditions and levels of inputs, the suitability of crops in relation to both rain-fed and irrigated conditions and to quantify the expected attainable production of cropping activities as relevant under the specific agro-ecological context. The characterization of agroclimatic and land resources includes components of climate, soils, landform, and present land cover. The simulations of crop growth dynamics in AEZ are based on daily thermal and moisture conditions.

\subsubsection{Thermal regime}

Thermal conditions are crucial in regulating crop growth and development. In AEZ, the effect of temperature on crop growth is characterized in each grid-cell by thermal regimes, which can be represented by temperature sums and length of temperature growing periods. Reference temperature sums are calculated for each gridcell by accumulating daily average temperatures $\left(T_{\mathrm{a}}\right)$ for days when $T_{\mathrm{a}}$ is above the respective threshold temperatures $\left(5\right.$ and $\left.10^{\circ} \mathrm{C}\right)$. The length of the temperature growing period is calculated as the number of days in the year when $T_{\mathrm{a}}$ exceeds the respective temperature threshold.

\subsubsection{Evapotranspiration}

The reference evapotranspiration $\left(E T_{0}, \mathrm{~mm} /\right.$ day $)$ is a general indicator of ecosystem water demand, represents evapotranspiration from a defined reference surface, which closely resembles an extensive surface of green, well-watered grass of uniform height $(0.12 \mathrm{~m})$, actively growing and completely shading the ground. AEZ calculates $E T_{0}$ from the attributes in the climate database for each grid-cell according to the Penman-Monteith equation. 
The actual uptake of water for the reference crop is characterized by the actual evapotranspiration $\left(E T_{a}\right)$ in a grid-cell. The daily water balance calculation of $E T_{a}$ differentiates two possible cases depending on the availability of water for plant extraction. When enough moisture is stored in the soil profile and water is not limiting, the $E T_{a}$ value is equal to the maximum evapotranspiration $\left(E T_{0}\right)$ of the reference crop. Under limiting water conditions, $E T_{a}$ is a fraction of the crop-specific potential evapotranspiration $\left(E T_{m}\right)$, depending on soil water availability. The details of the $E T_{a}$ calculation is long and highly technical, and can be found in AEZ model documentation (IIASA/FAO, 2010).

\subsubsection{Humidity index}

The humidity index is calculated as the ratio of precipitation to $E T_{0}$ multiplied by 100 . The index is calculated for the whole year, for the 6-month periods of April to September and October to March, and for seasonal 3 -month periods. An index value of more than 100 characterizes a situation when available precipitation exceeds reference evaporative demand. Index values below 100 signal periods of rainfall deficit.

\subsubsection{Length of growing season}

The agroclimatic potential productivity of land is closely associated with the number of days during the year when temperature regime and moisture supply are conducive to crop growth and development. In the AEZ methodology this period is termed the length of the growing period (LGP, days). In a formal sense, LGP refers to the number of days when average daily temperature is above $5^{\circ} \mathrm{C}$ and $E T_{\mathrm{a}}$ exceeds a certain fraction of $E T_{0}$, usually specified in the range of $0.4-0.5$. This is considered to delineate periods when sufficient water is available in the soil profile to allow the cultivation of annual crops.

Under irrigated condition, the length of the 'temperature growing period' $\left(\mathrm{LGP}_{\mathrm{t}}\right)$ is calculated as the number of days in the year when average daily temperature is above a temperature threshold ' $t$ '. In this study, the length of thermal growing season above $10{ }^{\circ} \mathrm{C}$ (TGS10), i.e. the number of days in a year with average daily temperature exceeding $10^{\circ} \mathrm{C}$, was computed for the baseline period 1961-1990 and for a range of RCM-based climate scenarios.

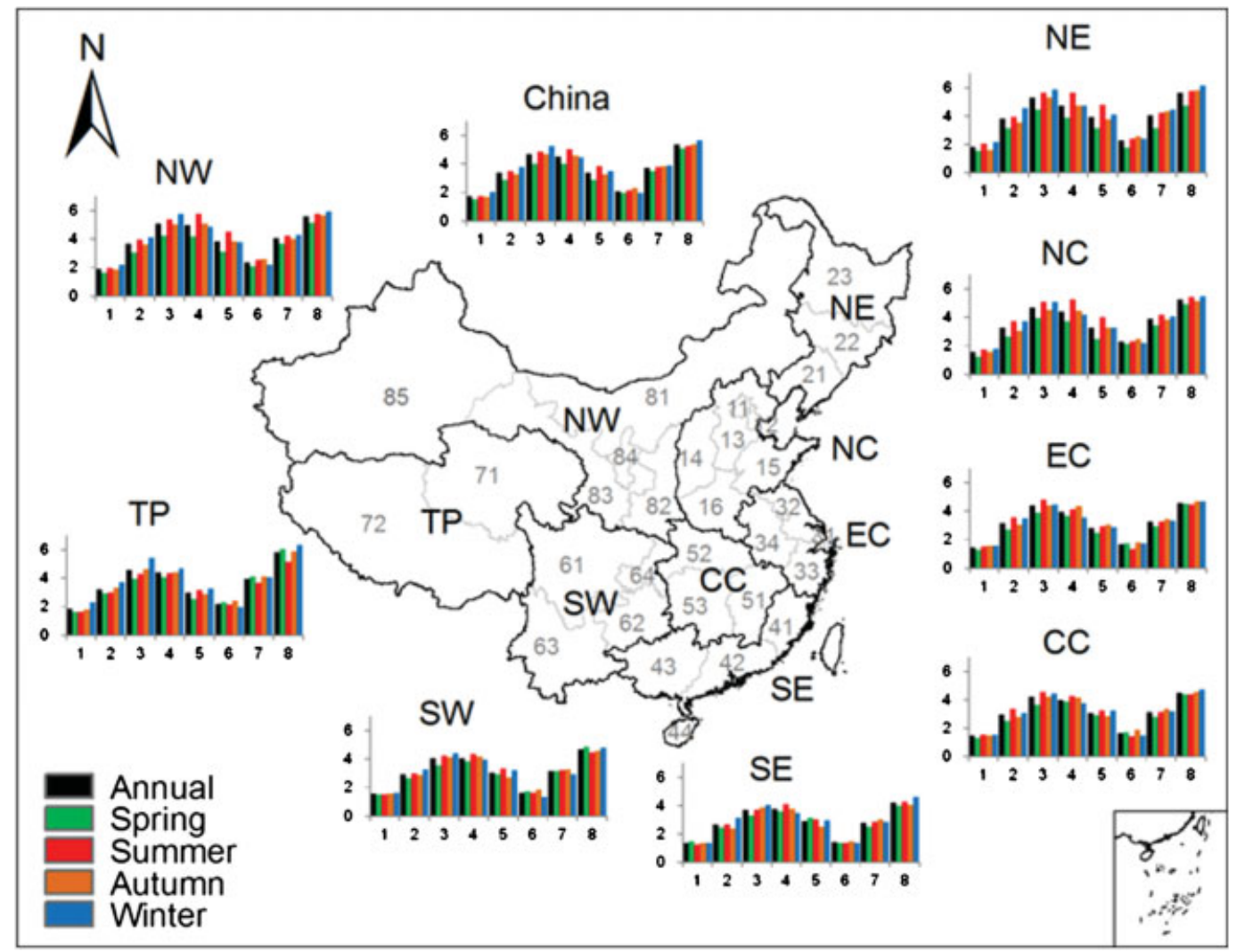

Figure 1. Changes in temperature in the eight regions of China between baseline (1961-1990) and the predictions of PRECIS and RegCM3 for 2020s, 2050s, and 2080s under the selected $\mathrm{CO}_{2}$ emission scenarios (1: PRECIS A1B 2020s; 2: PRECIS A1B 2050s; 3: PRECIS A1B 2080s; 4: PRECIS A2 2080s; 5: PRECIS A1B 2080s; 6: RegCM3 A1B 2020s; 7: RegCM3 A1B 2050s; and 8: RegCM3 A1B 2080s). Note. The North China (NC) includes Beijing (11), Tianjin (12), Hebei (13), Shanxi (14), Shandong (15), and Henan (16); Northeast (NE) includes Liaoning (21), Jilin (22), and Heilongjiang (23); East (EC) includes Shanghai (31), Jiangsu (32), Zhejiang (33), and Anhui(34); Southeast (SE) includes Fujian (41), Guangdong (42), Guangxi (43), and Hainan (44); Central (CC) includes Jiangxi (51), Hubei (52), and Hunan (53); Southwest (SW) includes Sichuan (61), Guizhou (62), Yunnan (63), and Chongqing (64); Plateau (TP) includes Qinghai (71) and Tibet (72); and Northwest (NW) includes Inner Mongolia (81), Shan’xi (82), Gansu (83), Ningxia (84), and Xinjiang (85). 


\subsection{Climate change scenarios}

PRECIS has become incredibly popular in the impact assessment community because of its attractiveness to national/regional weather services and related research institutions for building climate change scenarios which draw on local climate expertise. It was designed by the UK Met Office Hadley Centre to run on a Linux-based $\mathrm{PC}$ and to generate detailed climate change predictions at a $50 \times 50 \mathrm{~km}$ scale. PRECIS is driven by initial and boundary conditions computed with HadAM3P, which is the updated version of the atmospheric component of the Hadley Centre coupled ocean-atmosphere GCMHadCM3 (Xu et al., 2006). In this study, PRECIS is run for a geographical window covering China and its simulations for the baseline period of 1961-1990 are corrected based on observational records from 751 meteorological stations across China. Xu et al. (2006) conducted a test on the applicability of the PRECIS model to the Chinese climate by comparing historical temperature and rainfall data over China for 1961-1990 with modelled data for this baseline period. The test shows a generally good agreement between observed and simulated data. The spatial correlation coefficient between model simulation and observation for the baseline run is 0.95 for annual temperature and 0.75 for annual precipitation, respectively. This test provides confidence in the prediction results of PRECIS for China's climate in the
21 st century under the future scenarios of greenhouse gas emission as described in the IPCC Special Report on Emission Scenarios (SRES).

Another popular RCM employed in this study is the RegCM3 model, which is based on the model of Giorgi et al. (1993a, 1993b) and includes the upgrades of Pal et al. (2007). For the simulations with RegCM3, initial and time evolving lateral boundary conditions at 6-h intervals for temperature, surface pressure, wind and specific humidity, are provided by the CCSR/NIES/FRCGC MIROC3.2_hires simulations under the IPCC SRES A1B scenario, and a 150 year (1951-2100) transient simulation is conducted (Gao et al., 2012). The horizontal grid spacing of RegCM3 is $25 \mathrm{~km}$, and the model domain covers the whole of China and surrounding East Asia areas. Gao et al. (2012) validate the model performance and show that the spatial correlation coefficient between model simulation and observation is 0.95 and 0.98 for temperature and 0.58 and 0.82 for precipitation in winter and summer, respectively.

To further downscale the outputs of both PRECIS and RegCM3 simulations for AEZ application at the $10 \times 10 \mathrm{~km}$ resolution, an inverse distance weighted (IDW) interpolation in ArcGIS software is performed. For temperature interpolation, monthly or daily data are first reduced to sea level, then spatially interpolated using IDW, and then corrected to the actual altitude of individual $10 \times 10 \mathrm{~km}$ grid-cell.

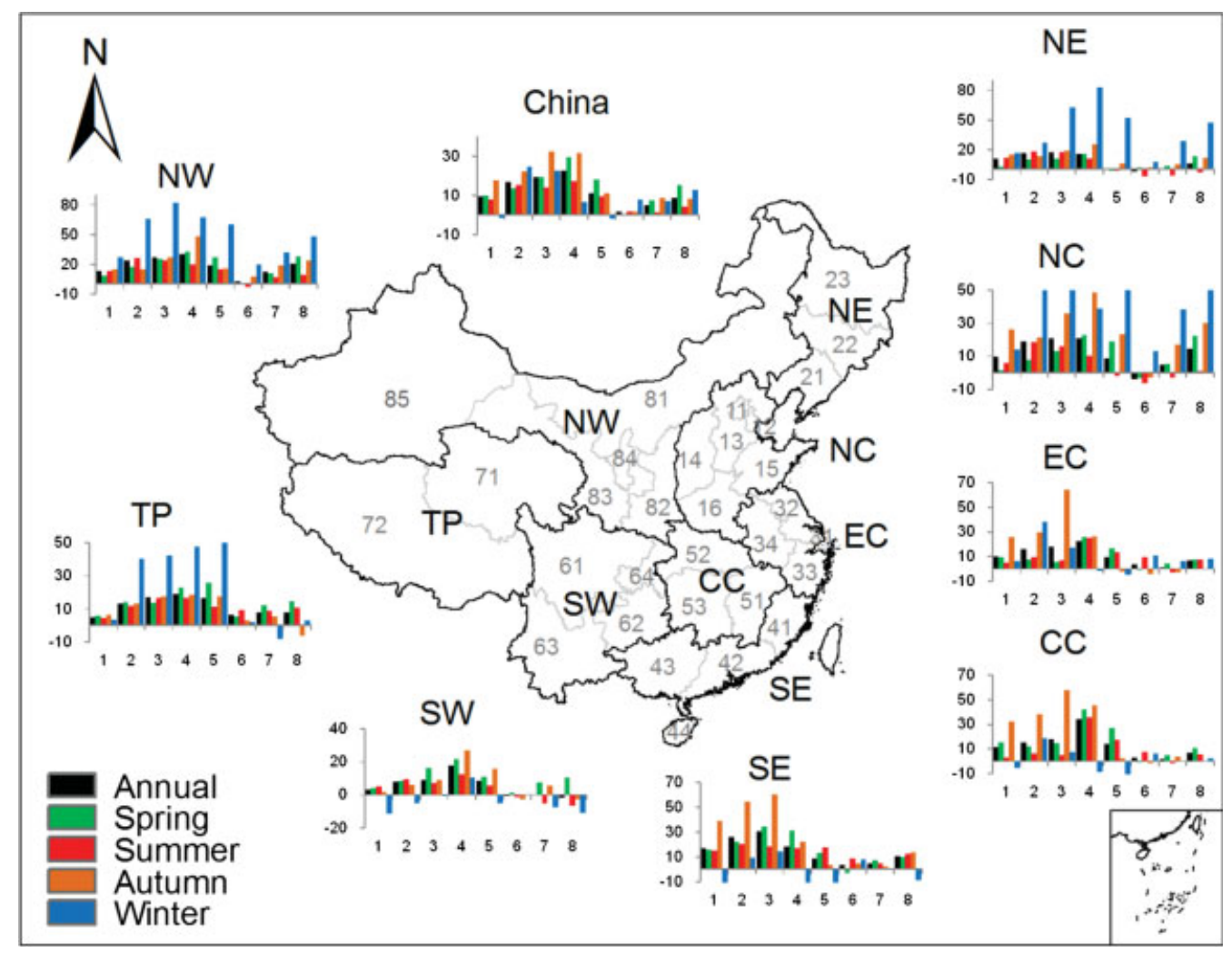

Figure 2. Changes in precipitation (\%) in the eight regions of China between baseline (1961-1990) and the predictions of PRECIS and RegCM3 for 2020s, 2050s, and 2080s under the selected $\mathrm{CO}_{2}$ emission scenarios (1: PRECIS A1B 2020s; 2: PRECIS A1B 2050s; 3: PRECIS A1B 2080s; 4: PRECIS A2 2080s; 5: PRECIS A1B 2080s; 6: RegCM3 A1B 2020s; 7: RegCM3 A1B 2050s; and 8: RegCM3 A1B 2080s). 
(a)

(b)

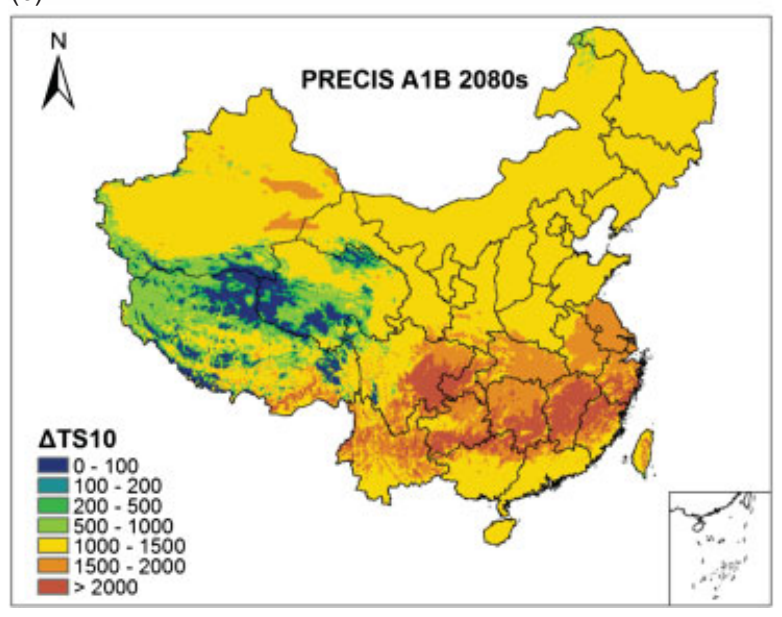

(c)

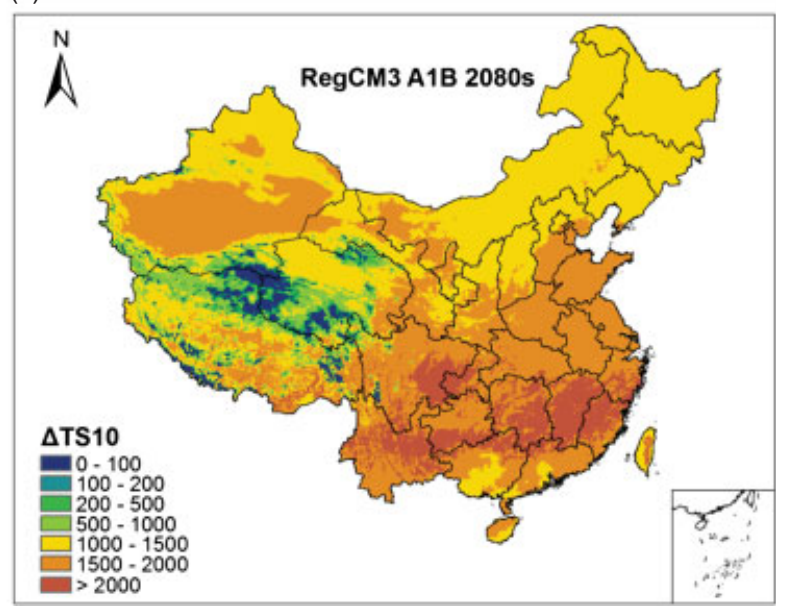

Figure 3. (a) Annual temperature sum above $10^{\circ} \mathrm{C}$ (TS10) under the baseline (1961-1990) climate (the map) and the percentage change in TS10 between the baseline and predictions for eight regions (column charts); change in TS10 for (b) PRECIS and (c) RegCM3 in 2080s under A1B scenarios.

\section{Results}

\subsection{Climate changes over China}

Figures 1 and 2 report the regional and national changes in temperature and precipitation from the baseline (1961-1990) climate to the predictions of PRECIS and RegCM3 under three $\mathrm{CO}_{2}$ emission scenarios. The changes are presented for the annual average and for each of the four seasons. To show regional variations of our assessment results, this study groups Chinese provinces into eight regions as shown in the note of Figure 1. The warming trend is confirmed in every region by the indicator of annual mean temperature in all combinations of RCMs and $\mathrm{CO}_{2}$ emission scenarios. At the national level, the rising of annual mean temperature from the baseline to the 2080s will be between $3.38^{\circ} \mathrm{C}$ (PRECIS-B2) and $5.34{ }^{\circ} \mathrm{C}$ (RegCM3-A1B). Under the same scenario A1B, prediction of RegCM3 is warmer in every region than that of PRECIS. With the same RCM PRECIS, A1B produces the warmest climate in comparison with $\mathrm{A} 2$ and $\mathrm{B} 2$, with is coincident with the magnitude of the respective emission trajectories. While the temperature in the 2080s are moderately higher under $\mathrm{A} 1 \mathrm{~B}$ than under $\mathrm{A} 2$, they are more than $1.0^{\circ} \mathrm{C}$ warmer under $\mathrm{A} 1 \mathrm{~B}$ and $\mathrm{A} 2$ than under $\mathrm{B} 2$ in seven of the eight regions except the southeast China.

In terms of regional variation, the results show that the northern part of China will experience sharper warming than the southern part. In more detail, for PRECIS projections to the end of this century, the Northeast and Northwest regions will experience the most significant increase in warming by $5.3{ }^{\circ} \mathrm{C}$ and $5.1{ }^{\circ} \mathrm{C}$, respectively. For RegCM3 projections, the Plateau, Northeast and Northwest regions will experience even more significant increase in warming, by the extent of $5.9,5.6$, and $5.6{ }^{\circ} \mathrm{C}$, respectively, and closely followed by the North region at $5.2^{\circ} \mathrm{C}$. In comparison, warming in the southeastern part of China will be less dramatic.

The simulations of most GCMs tend to show greater warming in winter compared to summer over China (Jiang et al., 2004; Zhou and Yu, 2006). Observational studies also report greater warming during cold seasons in recent decades (Tang and Zhai, 2005). In contrast, simulations from both RCMs indicate a warming of 
(a)

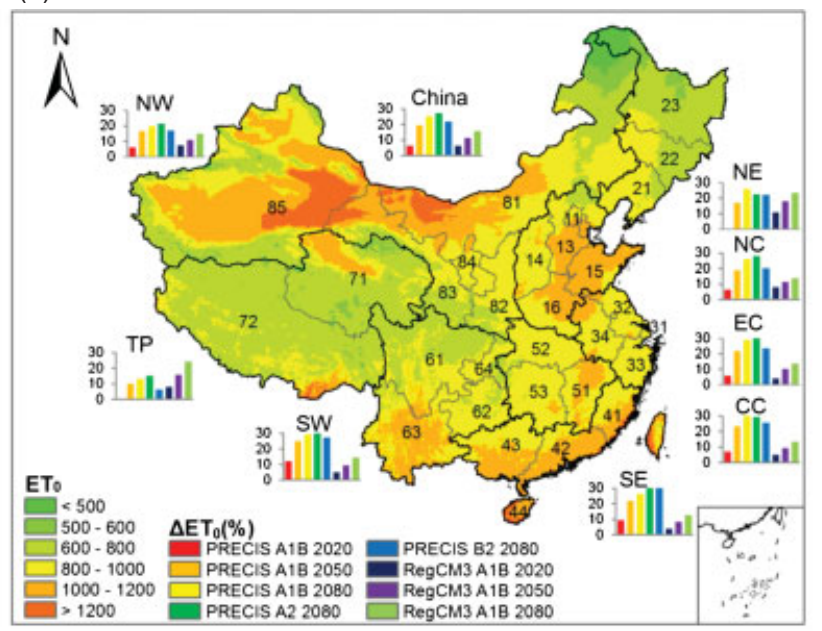

(b)

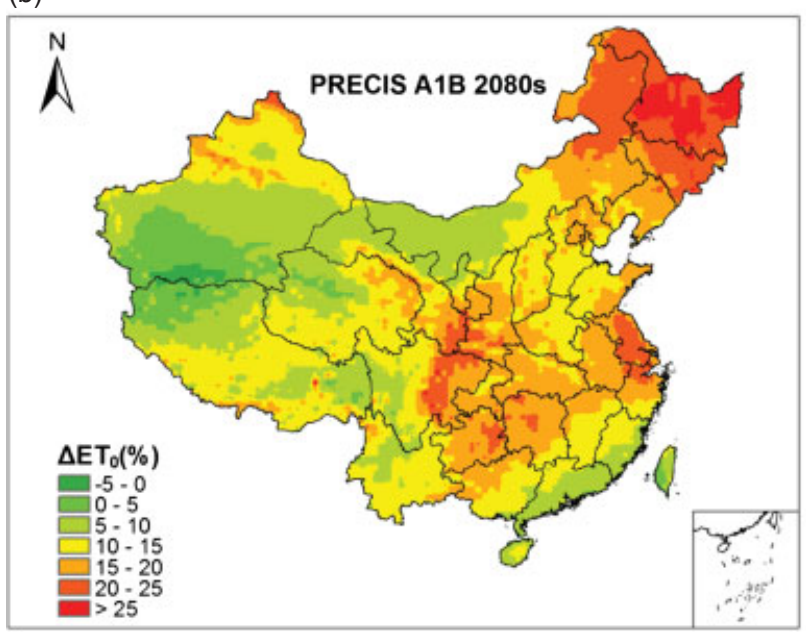

(c)

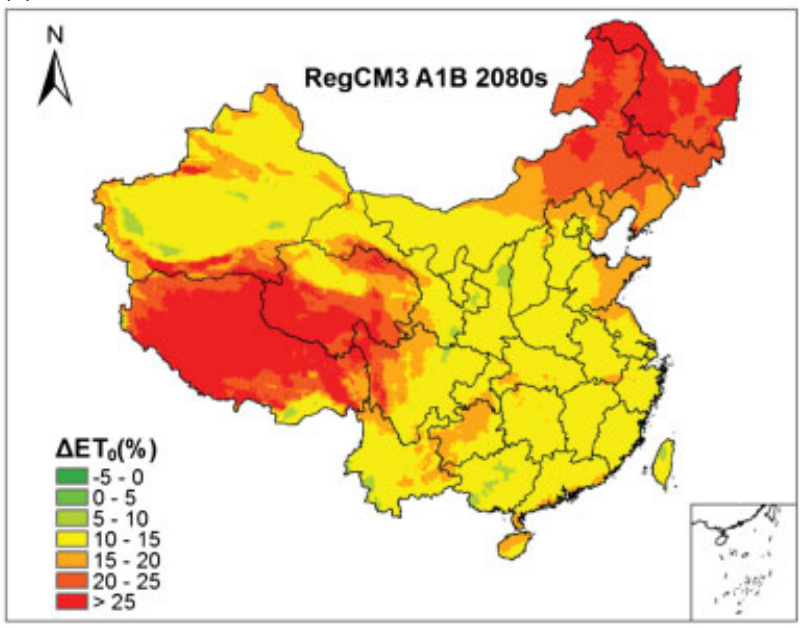

Figure 4. (a) Annual reference evapotranspiration $\left(E T_{0}\right)$ under the baseline (1961-1990) climate (unit: mm) (the map) and the percentage change in $E T_{0}$ between the baseline and predictions for eight regions (column charts); percentage change in $E T_{0}$ for (b) PRECIS and (c) RegCM3 in 2080s under A1B scenarios.

similar magnitude for summer, winter and annual mean, with a slightly higher magnitude for winter. In most cases, the weakest warming are suggested for spring. This contrast suggests that further investigation is needed to better understand the mechanisms involved.

At the national level, the trend of increasing precipitation is confirmed by the simulations of both RCMs. By the end of this century, the PRECIS-A2 combination shows an increase of precipitation by $22.3 \%$, followed by $21.6 \%$ of the PRECIS-A1B, $12.8 \%$ of the RegCM3-A1B, and $11.4 \%$ of the PRECIS-B2. There are obvious variations in the predictions produced by these two RCMs at the regional level. PRECIS simulations suggest precipitation increases in every region, most significantly in the Northwest and Southeast; whereas RegCM3 simulations indicate annual rainfall decreases in the North, Northeast and Southwest regions by the 2020s, and continued rainfall decrease in Southwest region by the 2080s. Both RCMs suggest that the already rainy southeast China will become wetter and the precipitation will increase significantly in the Northwest.
In terms of seasonal precipitation changes, RegCM3 simulations indicate that an increase of precipitation in summer over the Northwest, Southeast, and East and a decrease in the same season over Tibet, the Northeast, and Southwest by the 2080s; whereas the PRECIS projections suggest that the Northwest and Southeast will experience the most significant increase of precipitation in summer. Both RCMs suggest significant precipitation increases in winter in the north part of China and the Plateau region, also more rainfall in autumn in the south part of China.

\subsection{Impacts on thermal conditions}

Crops require sufficient warmth to develop through their growth stages. The effective accumulated temperature sum above $10{ }^{\circ} \mathrm{C}$ (TS10), which is measured as the sum of daily temperature for the period of daily mean temperature above $10{ }^{\circ} \mathrm{C}$, is arguably the most popular indicator for characterizing thermal growing conditions in China (Zhang and Zhu, 1959; Qiu, 1986; Zheng et al., 2010). Figure 3(a) presents the spatial distribution of TS10 over China under the baseline (1961-1990) climate 
(a)

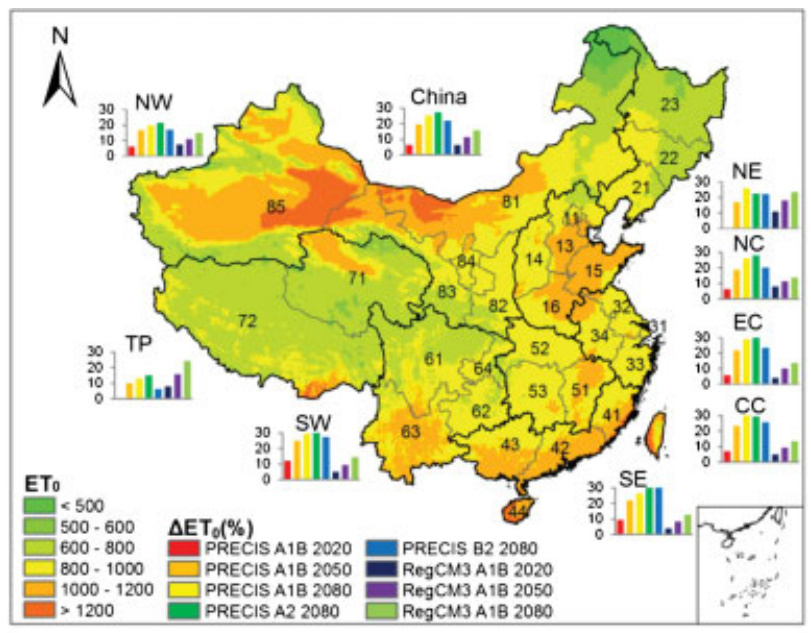

(b)

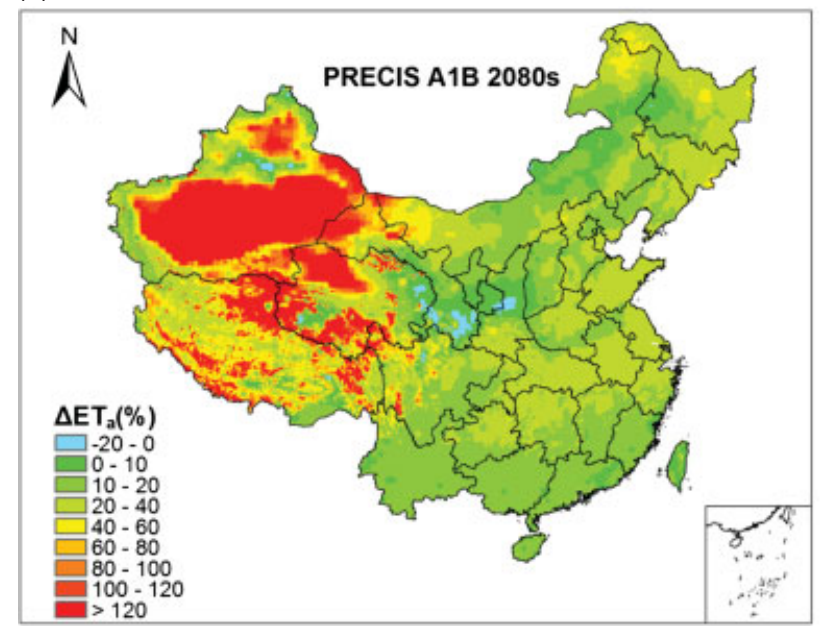

(c)

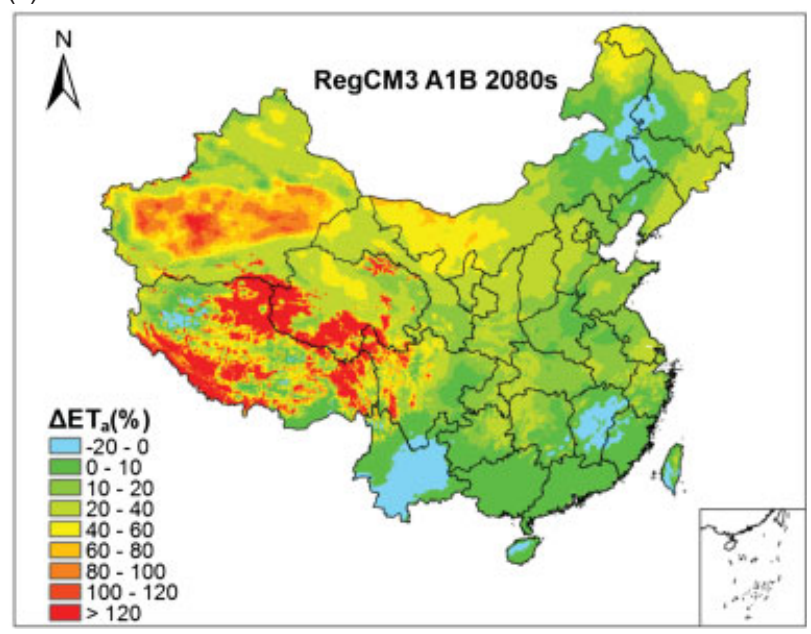

Figure 5. (a) Annual actual evapotranspiration $E T_{a}$ under the baseline (1961-1990) climate (the map) and percentage change in $E T_{a}$ between the baseline and predictions for 8 regions (column charts); percentage change in $E T_{a}$ for (b) PRECIS, and (c) RegCM3 in 2080 s under A1B scenarios. Note. Crop choices for calculating $E T_{a}$ are based on a combination of multi-cropping feasibility and major crop rotation groups reported in agricultural statistics at the county level.

conditions. TS10 depends largely on altitude and latitude, with the lowest values below $2000{ }^{\circ} \mathrm{C}$ in the Plateau and Great Xing'an Mountain areas of the Northeast region, and the highest values above $8000{ }^{\circ} \mathrm{C}$ across Leizhou Peninsula and Hainan Province in south China.

Figure 3(a) also reports, in column charts, the average changes in TS10 at the regional level from the baseline (1961-1990) climate to the predictions of PRECIS and RegCM3 under three $\mathrm{CO}_{2}$ emission scenarios. It shows that both RCMs predict overall increases in TS10 across China, but with large variations across regions. The results of PRECIS and RegCM3 simulations are generally consistent under A1B scenario over different future climatological periods (Figure 3(b) and (c)). In more detail, both models suggest that TS10 increases are most pronounced in the Plateau region, followed by the Northwest and Northeast at much reduced growth rates. Variations across the emission scenarios of $\mathrm{A} 1 \mathrm{~B}$ and A2 are very small, whereas PRECIS simulation under B2 produces lowest increase of TS10 in every region.
In brief, the results indicate that climate warming will significantly improve the thermal growing conditions in regions with high latitude and high altitude.

\subsection{Impacts on evapotranspiration}

Figure 4(a) presents the spatial distribution of annual reference evapotranspiration $\left(E T_{0}\right)$ for the baseline period 1961-1990. $E T_{0}$ critically depends on temperature and hence altitude and latitude. Low annual $E T_{0}$ in the Plateau and Northeast regions coincides with high altitudes and/or northern latitudes of these areas. The annual high $E T_{0}$ in south China corresponds with high temperatures. In addition, the high $E T_{0}$ in arid areas in northwest China and Inner Mongolia is exacerbated by low levels of relative humidity, and long sunshine duration there. Figure 3(a) also summarizes, in column charts, the percentage changes in $E T_{0}$ at the regional level between the baseline (1961-1990) and predictions of PRECIS and RegCM3 under three $\mathrm{CO}_{2}$ emission scenarios. It shows that the $E T_{0}$ will increase across the 8 regions in line 
with the increase in temperature as presented in Figure 1, with the exception of the Plateau region. While the PRECIS simulations show that $E T_{0}$ in the Plateau displays the weakest changes (Figure 4(b)), RegCM3 simulations suggest the opposite - the most significant increase in $E T_{0}$ will occur in the Plateau region, and then closely followed by the Northeast region (Figure 4(c)). Also in line with the increases in temperature under different scenarios, PRECIS simulations produce the lowest increases in $E T_{0}$ under B2 scenario.

The spatial pattern of the annual actual evapotranspiration $\left(E T_{a}\right)$ under the baseline climate is shown in Figure 5(a). The southeastward increase in annual $E T_{a}$ from $50 \mathrm{~mm}$ in Northwest to $1000 \mathrm{~mm}$ in Southeast resembles the pattern of precipitation over China. For humid areas the annual $E T_{a}$ is clearly lower than the annual precipitation. In most parts of China, the change in precipitation dominates the change in $E T_{a}$ except for Southeast region where changes in $E T_{0}$ is the major driving factor. For the percentage changes in $E T_{a}$ at the regional level, the column charts in the figure show that all regions in general and Plateau and Northwest regions in particular will experience significant increase in $E T_{a}$, which are largely in agreement with the simulated increasing of precipitation as presented in Figure 2. Under the same A1B scenario, PRECIS simulations suggest a more significant increasing in $E T_{a}$ across seven of the eight regions except Plateau, owing to the wetter condition from this model in comparison with the simulations of RegCM3. Interestingly, the simulations of both RCMs show that the most significant increase of $E T_{a}$ will occur in the Xinjiang province and Plateau region (Figure 5(b) and (c)).

\subsection{Impacts on moisture conditions}

Under the baseline climate, the humidity index (HI), i.e. the radio of precipitation over $E T_{0}$, shows a very distinct gradient (Figure 6(a)), with the highest values in southeast China, where annual precipitation exceeds 1.5 times the $E T_{0}$, to the lowest values well below 25 in the Northwest and the north of the Plateau region. Figure 6(a) further shows that climate change

(a)

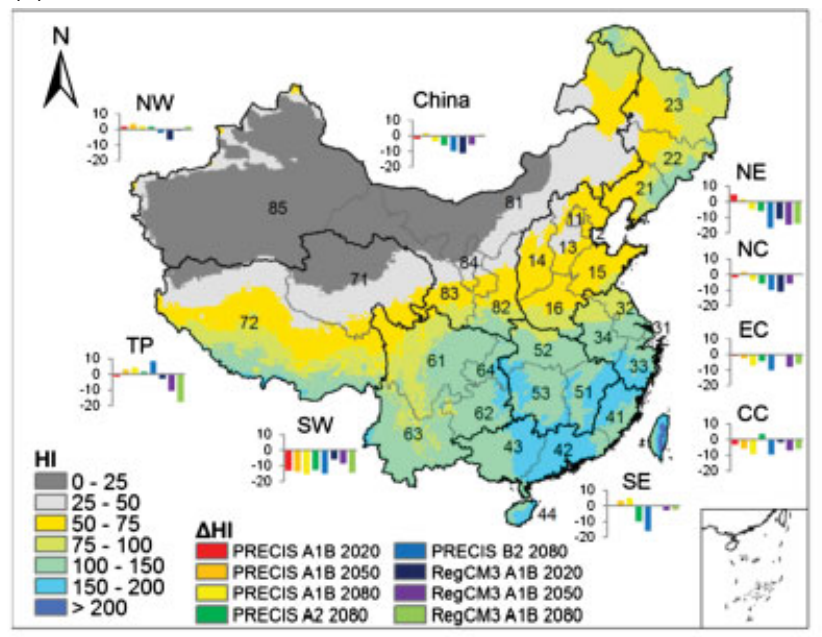

(b)

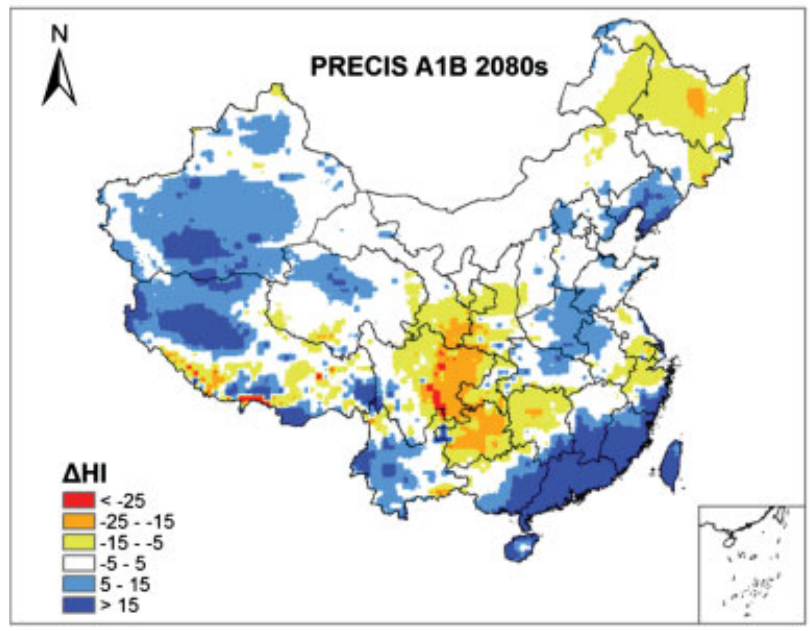

(c)

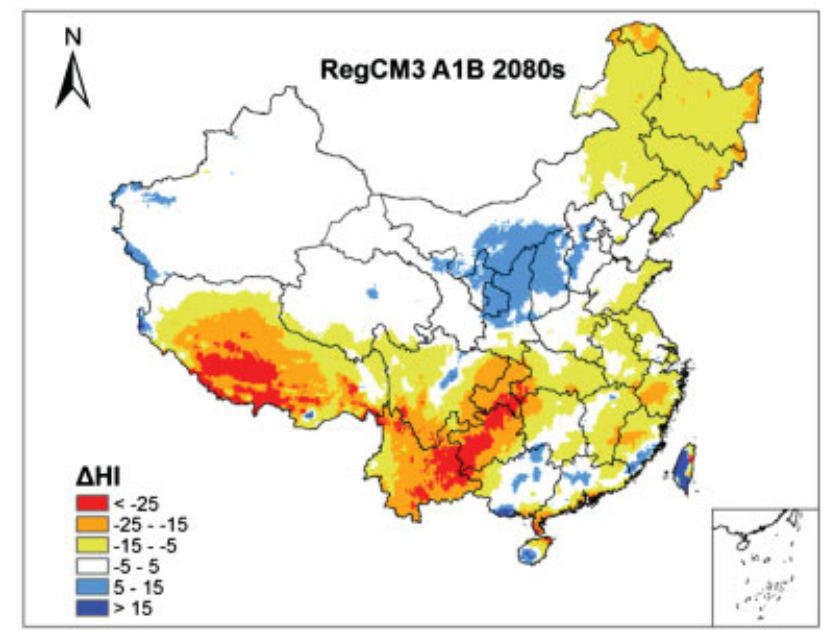

Figure 6. (a) Humidity index (HI) under the baseline (1961-1990) climate (the map) and the changes in HI between the baseline and predictions for eight regions (column charts); changes in HI for (b) PRECIS and (c) RegCM3 in 2080s under A1B scenarios. 
will influence future moisture conditions throughout China. The column charts there indicate that under the A1B scenario, the RegCM3 projections indicate that all eight regions will generally experience decrease in the Precipitation $/ E T_{0}$ ratio. The results for the Northwest imply that the simulated increase in precipitation is insufficient to alleviate the arid condition in the region for the 2020s and 2050s. The Northeast will be much drier due to the decrease in precipitation, especially in summer.

The PRECIS projections also suggest generally decreasing humidity for 2080s under three $\mathrm{CO}_{2}$ scenarios, with the exception of the Southeast, Northwest, and north Plateau region (Figure 6(b)). The results of PRECIS-A1B and PRECIS-A2 combinations suggest that the arid condition in the Northwest will be alleviated because of more precipitation in the 2080s. While the PRECIS simulations show that HI will generally increase with more precipitation in the Plateau, RegCM3 simulations suggest the opposite - the most significant decrease in $\mathrm{HI}$ will occur in the Plateau region due to the reduction of precipitation. It is worth highlighting that all results for the Southwest from both RCMs show significant reduction in the value of HI. It is also worth noting that severe drought has already occurred frequently in recent years in this region. The combination of these two sets of results implies severe challenges for future agricultural development in the Southwest region.

Figure 7(b) and (c) further show that the HI in the summer half-year (Q2 and Q3) will decrease in Southwest and increase in Southeast across all simulation results. However, the two RCMs produce opposite changes for Q3 in the Northeast, North, Northwest and Tibetan Plateau, in line with the precipitation projections from each of the RCMs. For the winter half-year (Q1 and Q4), consistent increases in the Northwest and North are produced by all simulations but opposite changes are produced in other regions (Figure 7(a) and (d)). Generally speaking, in most regions of China PRECIS and RegCM3 projections under A1B scenario indicate opposite directions for the changes of the HI implying considerable uncertainties in projecting future humidity condition. (a)

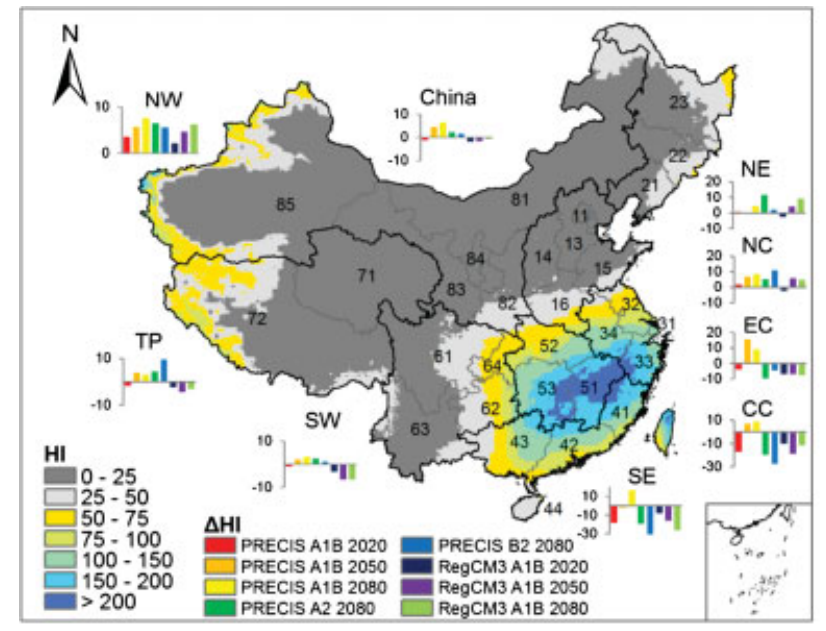

(c)

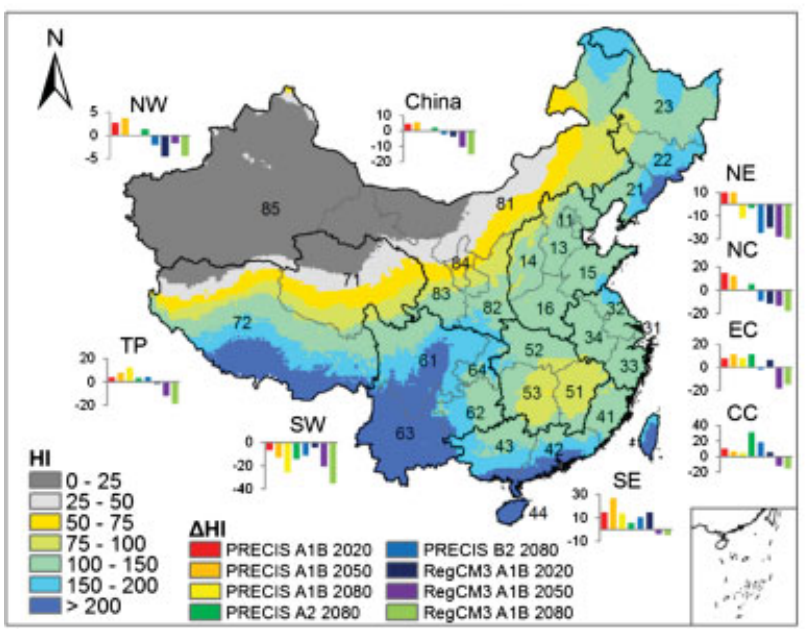

(b)

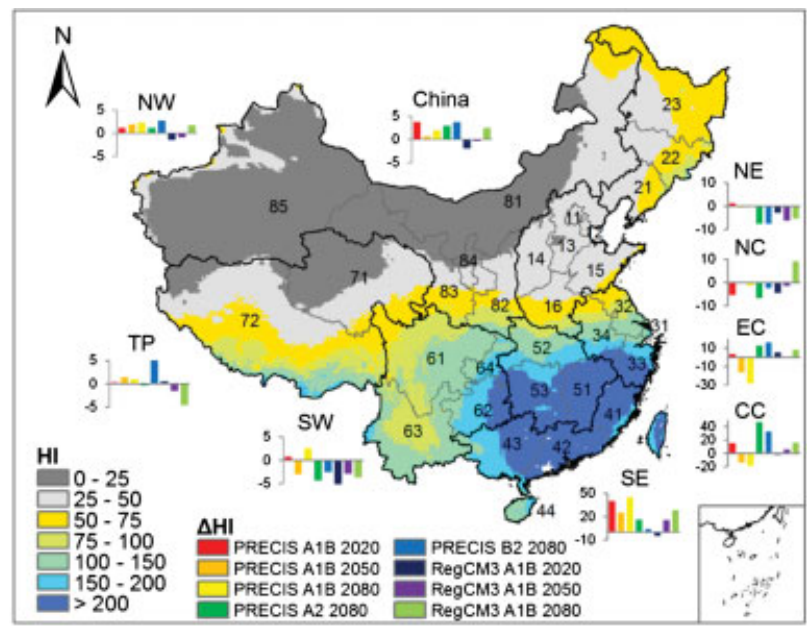

(d)

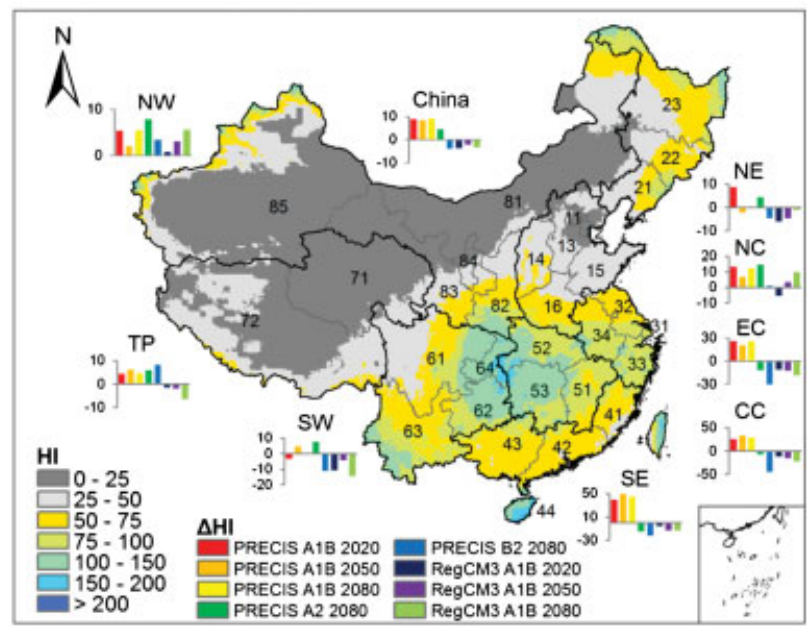

Figure 7. HI under the baseline (1961-1990) climate (the map) and the changes in HI between the baseline and predictions for eight regions (column charts): (a) January to March, (b) April to June, (c) July to September, and (d) October to December. 
(a)

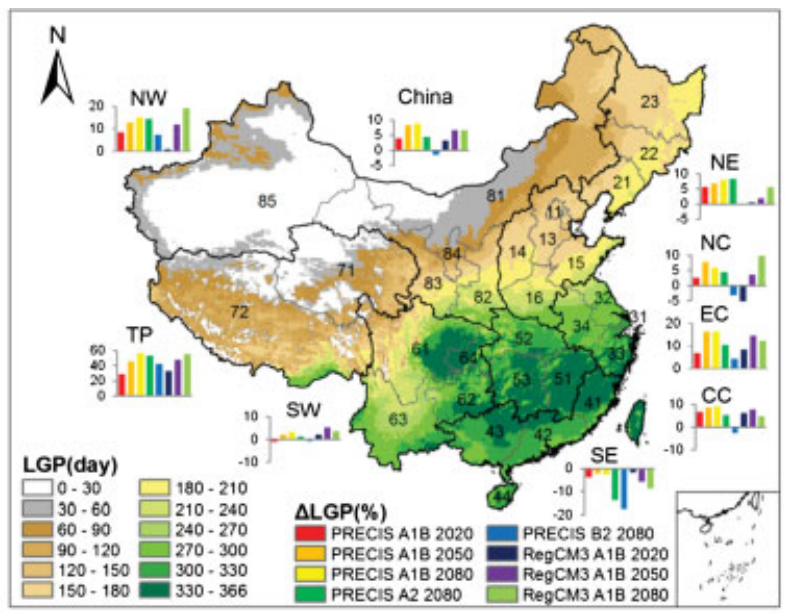

(b)

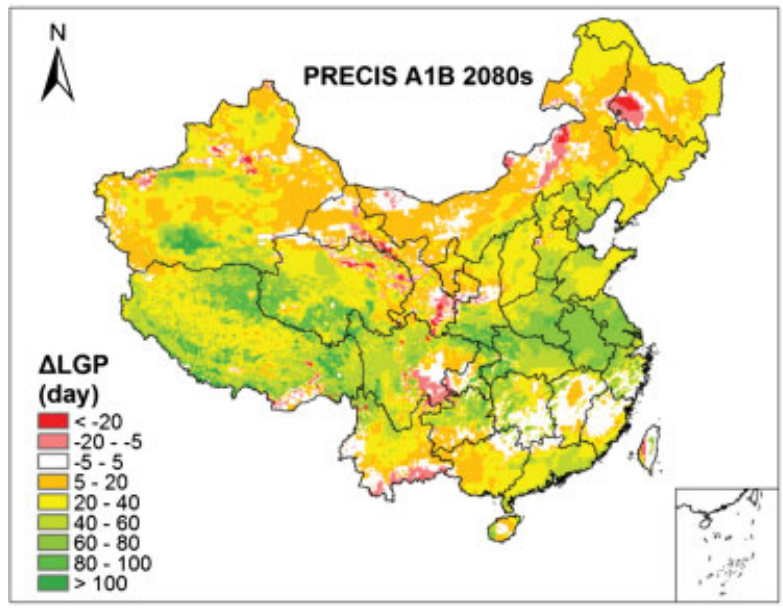

(c)

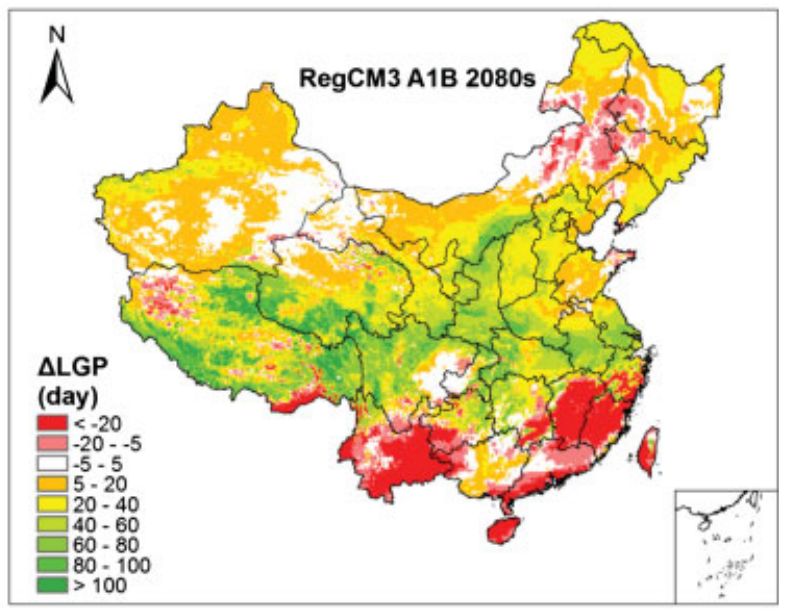

Figure 8. (a) Length of growth period (LGP) under the rain-fed condition and the baseline (1961-1990) climate (the ma) and the percentage changes in LGP between the baseline and predictions for eight regions (column charts); changes in LGP for (b) PRECIS and (c) RegCM3 in 2080s underA1B scenarios.

\subsection{Impacts on length of growing period and season}

\subsubsection{Length of growing period (LGP) under rain-fed} condition

Figure 8(a) depicts the spatial distribution of LGP under rain-fed conditions and the baseline climate. It shows that northwest China and north Qinghai-Tibet Plateau have shortest length of growing period mainly owing to arid and alpine-cold conditions there respectively. Sichuan Basin and southeast China enjoy the longest length of growing period - more than 330 days per annum. The column charts in Figure 8(a) also show the percentage changes in LGP at the regional level between the baseline and future predictions of PRECIS and RegCM3 under $\mathrm{A} 1 \mathrm{~B}, \mathrm{~A} 2$ and B2 scenarios. The results of PRECIS-A1B, PRECIS-A2, and RegCM3-A1B for the 2050s and 2080s suggest relatively consistent extension in the LGP across six of the eight regions with the only exception of the Southeast and Southwest (Figure 8(b) and (c)). All simulations indicate that the most significant extension of the LGP is expected to occur on the Qinghai-Tibet Plateau, from 77 days in the baseline and 99 days in the 2020s, to 120 days in the 2080s under the PRECIS-A1B. They all also agree that a shortening of the growing period under rain-fed condition may occur in the Southeast region because this region already have enough thermal resource and higher temperature will have adverse effect on crops in the absence of irrigation. Departure from the consistent results of the above-mentioned three sets of simulations, the PRECIS-B2 simulation suggests that the North, Central, and Southwest regions will be likely to experience a shortening of growing period as well in the absence of irrigation.

\subsubsection{Length of thermal growing season above $10^{\circ} \mathrm{C}$ (TGS10)}

Under present-day condition, values of TGS10 range from close to zero in the Plateau region to year-round in the very southern part of China (Figure 9(a)). Because higher temperatures resulting from climate change will increase the length of the TGS10, all projections presented in the column charts of Figure 9(a) show similar pattern of TGS10 extension in each of the eight regions 
(a)

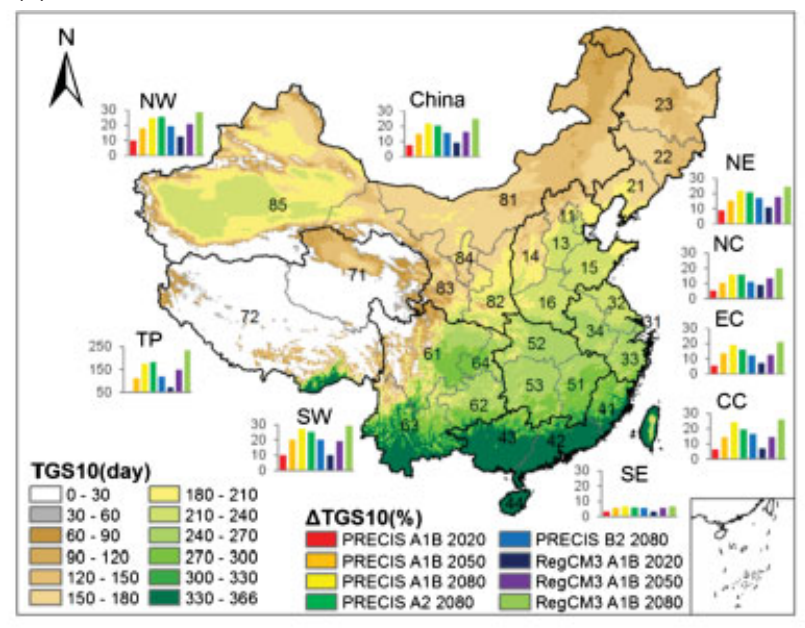

(b)

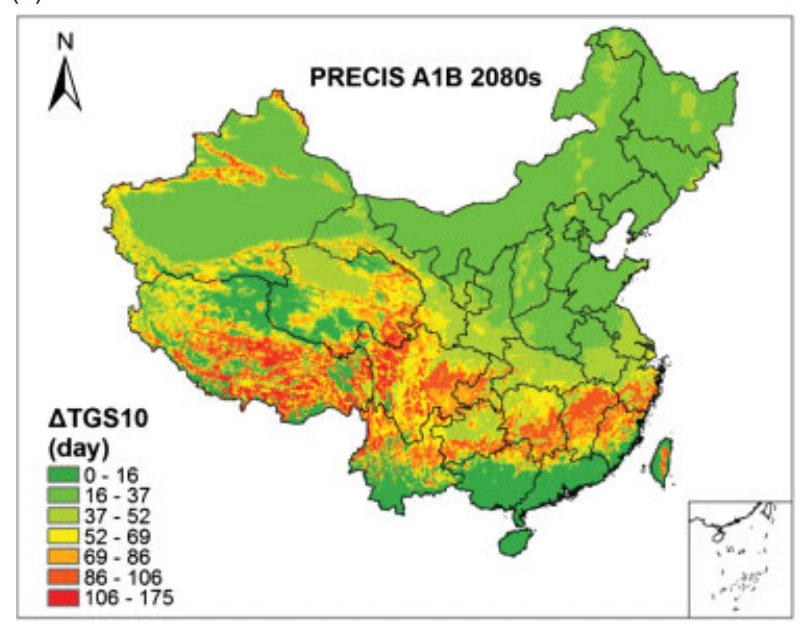

(c)

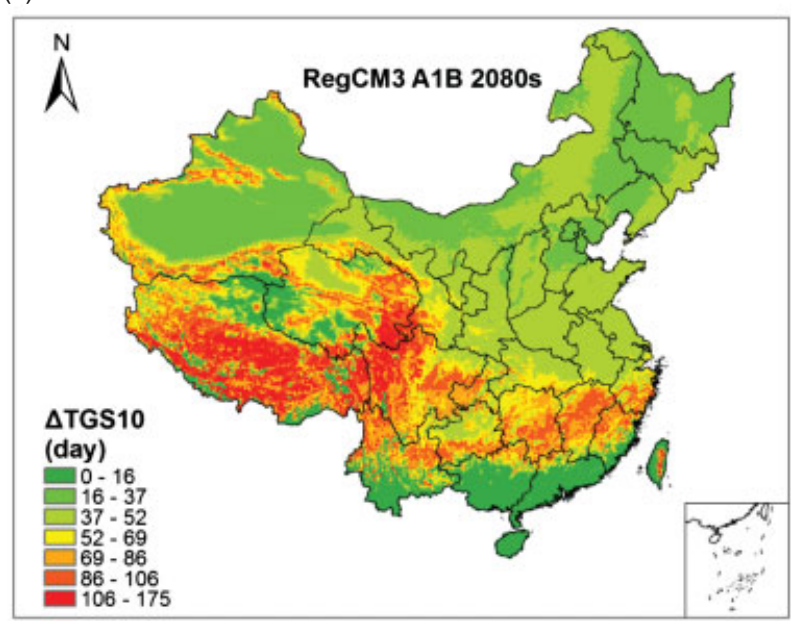

Figure 9. (a) Length of thermal growing season above $10^{\circ} \mathrm{C}$ (TGS10) under the baseline (1961-1990) climate (the map) and the percentage changes in TGS10 between the baseline and predictions for eight regions (column charts); changes in TS10 for (a) PRECIS and (b) RegCM3 in 2080s under A1B scenarios.

and RegCM3-A1B produces a higher rate of extension than PRECIS-A1B does in every region. TGS10 in the Plateau region will be almost tripled by the 2080s under PRECIS-A1B, from 30 days in the baseline climate to 83 days in the 2080s, and more than tripled to 101 days in the 2080s under RegCM3-A1B (Figure 9(b) and (c)). At the other end, TGS10 in the Southeast region will keep stable because daily average temperatures in the region exceeded $10^{\circ} \mathrm{C}$ almost every day already in the baseline. In other six regions, the range of TGS10 increase will be between 24 days (11.1\% under PRECIS-B2 in the North region) and 67 days (29.3\% under RegCM3-A1B in the Southwest).

\section{Discussion and conclusions}

To date, the existing projections of Chinese crop yields under climate change have been based mainly on the results of process-based crop-growth models. The present research complements these studies that have been performed so far for China and puts an emphasis on a more general notion of fundamental agroclimatic conditions that regulate the selection of cultivars and crop rotation schemes and furthermore the timing choices of field management operations, thus determining the total production potential of a given piece of land. While studies based on crop-growth models provide very detail assessment of how the crops actually respond to climate and how this response affects yield, the assessment of agroclimatic conditions provides more general information about which crops, cropping rotation schemes and/or farming technologies can be in general applied within the area concerned. Such assessments would help policy makers to understand the shifts in the patterns of key agroclimatic indicators, thus facilitating the development of macro-strategies for adjusting cropping structures, adopting suitable technologies, and developing adaptive infrastructures.

In this study, we have compared the baseline agroclimatic conditions of China to those expected in the near future (2020s), around the middle (2050s), and end (2080s) of the 21st century by the projections of two popular RCMs under three emission scenarios. This 
allows us to examine a set of key climate indicators that are obligatory in regulating crop growth and output. The combination of rising air temperature and changes in the amount and distribution of precipitation in the future will generally lead to a lengthening of the crop growing season and may significantly increase multi-cropping opportunities in most regions of China. Of course, to confirm the latter conjecture, more careful research on matching crop requirements and prevailing climate conditions is needed. Nevertheless, the present study confirms the substantial northward expansion of the thermal suitability of crop production in China under climate change. The extension of the crop growing period in central and northern China will have profound implications for regional agricultural production. Earlier onset of the growing season will favour earlier sowing of crop and a later cessation of the growing season may provide favourable conditions for the growth of crops in higher latitudes. In addition, the extension of the crop growing period is in tandem with rising temperatures during the growing season, which may advance the total production potentials per unit of cropland at high latitudes by increasing the potential number of harvests.

However, it is worth noting that the benefits of a lengthened growing season with higher temperatures may be counterbalanced by changes in the precipitation patterns, because a combination of them may reduce the humidity index in the summer half-year, especially in the arid and semi-arid regions where water has been a major limit factor for crop growth. The Qinghai-Tibetan Plateau with its high elevations will most likely experience improvement in agroclimatic conditions, however, as an ecologically fragile region, such improvement may not necessarily lead to increased potential for crop production. It is also noteworthy that both RCMs project drier condition in the Southwest region which already suffered from severe drought in recent years. The above discussion indicates that future work should focus on a spatially explicit match between improved agroclimatic conditions and the potential number of harvests.

To partially avoid the uncertainty caused by using a single climate model, we employ climate projections from two best available RCMs to assess the future agroclimatic conditions across China. The predicted increase in temperature is relatively consistent between the two RCMs and the projections of temperature-related indices generally show a good agreement as well. RegCM3 simulations generally show more significant increase in TS10 and thermal growing season above $10^{\circ} \mathrm{C}$, especially in the Plateau region. In contrast, the relatively large intermodal differences in precipitation, which demonstrates large uncertainties in projecting future precipitation changes, bring in considerable discrepancies in the estimation of precipitation-related agroclimatic index, such as evaporation and HI, between the two RCMs. Opposite changes for HI between the two RCMs can be found in most regions of China. Such discrepancies would add difficulties to the attempt to match improved agroclimatic conditions with the potential increase in multi-cropping opportunities.

Like most studies in the climate change impacts assessments, there are several sources of uncertainties and limitations in this study. Uncertainty in climate projection is one of the main sources of uncertainty in assessing the effect of climate change on agriculture using model simulation (Yao et al., 2011). While the dynamical downscaling may provide additional climate information, or 'add value' for the study of climate change and its potential impacts, the improvements depend essentially on the kind of application, experimental setup, analysed model variables, and location (Feser et al., 2011). Moreover, the skill of an RCM in dynamical downscaling application is highly dependent upon the skill of the driving GCM and the biases of an RCM are not necessarily smaller than that of the driving GCM (Wang et al., 2004). It is recognized that different GCM inputs and different RCMs would produce disparate spatial and temporal patterns of regional climate change scenarios (Gao et al., 2012). Recent study suggest that for climate change studies, highest priority should be given to improving the long-range climate skill of GCMs (Racherla et al., 2012). Therefore, multi-GCM and multi-RCM ensembles of climate change simulations would reduce uncertainty and achieve more scientifically robust and valuable conclusions in the projection of future regional climate change. Another limitation is related to driving the AEZ model by making use of a 30year averaged climatology, which may greatly weaken the seasonal variability of agroclimatic indices. Running the AEZ model year by year with seasonal mean climate conditions should represent seasonal variability better, but it would be inevitable to add a great uncertainty to the assessment due to the application of year-by-year climate change scenarios given the well-known scientific cautions on such yearly-presented scenarios.

\section{ACKNOWLEDGEMENTS}

The authors are very grateful to the two anonymous reviewers for their helpful comments and constructive suggestions, which led to a significant improvement in the original manuscript. We thank Dr. Radan Huth for reviewing our revised manuscript. This study was supported by National Natural Science Foundation of China (grants 41371110, 41371068, 40921140410). The authors would like to thank Dr. Xuejie Gao of National Climate Center for providing the RegCM3 climate Scenarios.

\section{References}

Dai SW, Yang XG, Zhao M, Li Y, Wang WF, Liu ZJ. 2011. Changes of China agricultural climate resources under the background of climate change II. Spatiotemporal change characteristics of agricultural climate resources in Southwest China. Chinese J. Appl. Ecol. 22(2): 442-452 (in Chinese).

Dong J, Liu J, Tao F, Xu X, Wang J. 2009. Spatio-temporal changes in annual accumulated temperature in China and the effects on cropping systems, 1980 s to 2000 . Climate Res. 40: 37-48. 
Feser F, Rockel B, von Storch H, Winterfeldt J, Zahn M. 2011. Regional climate models add value to global model data: a review and selected examples. Bull. Am. Meteorol. Soc. 92(9): 1181-1192.

Fischer G, van Velthuizen H, Shah M, Nachtergaele F. 2002. Global Agro-Ecological Assessment for Agriculture in the 21st Century: Methodology and Results. IIASA: Laxenburg, Austria.

Fischer G, Shah M, Tubiello FN, van Velhuizen H. 2005. Socioeconomic and climate change impacts on agriculture: an integrated assessment, 1990-2080. Philos. Trans. B 360: 2067-2083.

Fronzek S, Carter TR. 2007. Assessing uncertainties in climate change impacts on resource potential for Europe based on projections from RCMs and GCMs. Clim. Change 81: 357-371.

Gao XJ, Shi Y, Giorgi F. 2011. A high resolution simulation of climate change over China. Sci. China Earth Sci. 54(3): 462-472.

Gao XJ, Shi Y, Zhang DF, Giorgi F. 2012. Climate change in China in the 21 st century as simulated by a high resolution regional climate model. Chinese Sci. Bull. 57(10): 1188-1195.

Giorgi F, Marinucci MR, Bates GT. 1993a. Development of a SecondGeneration Regional Climate Model (RegCM2). Part I: BoundaryLayer and Radiative Transfer Processes. Mon. Weather Rev. 121(10): 2794-2813

Giorgi F, Marinucci MR, Bates GT, De Canio G. 1993b. Development of a second-generation regional climate model (RegCM2). Part II: Convective processes and assimilation of lateral boundary conditions. Mon. Weather Rev. 121(10): 2814-2832.

IIASA/FAO. 2010. Global Agro-ecological Zones (GAEZ v3.0). IIASA $\backslash$ FAO: Laxenburg, Austria $\backslash$ Rome, Italy.

Jiang D, Wang H, Lang X. 2004. Multimodel ensemble prediction for climate change trend of China under SRES A2 scenario. Chinese J. Geophys. 47(5): 878-886.

Li Y, Yang XG, Wang WF, Liu ZJ. 2010. Changes of China agricultural climate resources under the background of climate change I. Spatiotemporal change characteristics of agricultural climate resources in South China. Chinese J. Appl. Ecol. 21(10): 2605-2614 (in Chinese).

Meehl G, Covey C, Delworth T, Latif M, McAvaney B, Mitchell J, Stouffer R, Taylor K. 2007. The WCRP CMIP3 multi-model dataset: a new era in climate change research. Bull. Am. Meteorol. Soc. 88 : 1383-1394.

Moonen A, Ercoli L, Mariotti M, Masoni A. 2002. Climate change in Italy indicated by agrometeorological indices over 122 years. Agr. Forest. Meteorol. 111(1): 13-27.

Olesen J, Carter T, Díaz-Ambrona C, Fronzek S, Heidmann T, Hickler T, Holt T, Minguez M, Morales P, Palutikof J, Quemada M, RuizRamos M, Rubæk G, Sau F, Smith B, Sykes M. 2007. Uncertainties in projected impacts of climate change on European agriculture and terrestrial ecosystems based on scenarios from regional climate models. Clim. Change 81: 123-143.

Pal JS, Giorgi F, Bi X, Elguindi N, Solmon F, Rauscher SA, Gao X, Francisco R, Zakey A, Winter J. 2007. Regional climate modeling for the developing world: The ICTP RegCM3 and RegCNET. Bull. Am. Meteorol. Soc. 88(9): 1395-1409.

Piao S, Fang J, Zhou L, Ciais P, Zhu B. 2006. Variations in satellitederived phenology in China's temperate vegetation. Glob. Chang. Biol. 12(4): 672-685.

Piao S, Ciais P, Huang Y, Shen Z, Peng S, Li J, Zhou L, Liu H, Ma Y, Ding Y. 2010. The impacts of climate change on water resources and agriculture in China. Nature 467: 43-51.

Qian W, Lin X. 2004. Regional trends in recent temperature indices in China. Climate Res. 27(2): 119-134.

Qiu B. 1986. A new discussion on the regionalization of agroclimate in China. Acta Geographica Sinica 41(3): 202-209 (in Chinese)

Racherla PN, Shindell DT, Faluvegi GS. 2012. The added value to global model projections of climate change by dynamical downscaling: A case study over the continental U.S. using the
GISS-ModelE2 and WRF models. J. Geophys. Res. 117: D20118, DOI: 10.1029/2012JD018091.

Ren GY, Xu MZ, Chu ZY, Guo J, Li QX, Liu XN, Wang Y. 2005. Changes of surface air temperature in China during 1951-2004. Clim. Environ. Res. 10(4): 717-727 (in Chinese).

Solomon S, Qin D, Manning M, Alley RB, Berntsen T, Bindoff NL, Chen Z, Chidthaisong A, Gregory JM, Hegerl GC, Heimann M, Hewitson B, Hoskins BJ, Joos F, Jouzel J, Kattsov V, Lohmann U, Matsuno T, Molina M, Nicholls N, Overpeck J, Raga G, Ramaswamy V, Ren J, Rusticucci M, Somerville R, Stocker TF, Whetton P, Wood RA, Wratt D. 2007. Technical Summary. In Climate Change 2007: The Physical Science Basis. Contribution of Working Group I to the Fourth Assessment Report of the Intergovernmental Panel on Climate Change. Solomon S, Qin D, Manning M, Chen Z, Marquis M, Averyt KB, Tignor M, Miller HL (eds). Cambridge University Press: Cambridge, UK and New York, NY.

Sun Y, Zhang XQ, Zheng D. 2010. The impacts of climate warming on agricultural climate resources in the arid regions of Northwest China. J. Nat. Resour. 25(7): 1153-1162 (in Chinese).

Tang H, Zhai P. 2005. Comparison of variations of surface air temperatures in eastern and western China during 1951-2002. Chinese J. Geophys. 48: 526-534 (in Chinese).

Trnka M, Eitzinger J, Dubrovský M, Semerádová D, Štěpánek P, Hlavinka P, Balek J, Skalák S, Farda A, Formayer H, Žalud Z. 2010 Is rainfed crop production in central Europe at risk? Using a regional climate model to produce high resolution agroclimatic information for decision makers. J. Agric. Sci. 148: 639-656.

Trnka M, Eitzinger J, Semerádová D, Hlavinka P, Balek J, Dubrovský M, Kubu G, Štěpánek P, Thaler S, Možný M, Žalud Z. 2011a. Expected changes in agroclimatic conditions in Central Europe. Clim. Change 108: 261-289.

Trnka M, Olesen JE, Kersebaum KC, SkjelvÅG AO, Eitzinger J, Seguin B, Peltonen-Sainio P, RÖTter R, Iglesias ANA, Orlandini S, DubrovskÝ M, Hlavinka P, Balek J, Eckersten H, Cloppet E, Calanca P, Gobin A, VuČEtiĆ V, Nejedlik P, Kumar S, Lalic B, Mestre A, Rossi F, Kozyra J, Alexandrov V, SemerÁDovÁ D, ŽAlud Z. 2011b. Agroclimatic conditions in Europe under climate change. Glob. Chang. Biol. 17(7): 2298-2318.

Wang Y, Leung LR, McGregor JL, Lee D-K, Wang W-C, Ding Y, Kimura F. 2004. Regional climate modeling: progress, challenges, and prospects. J. Meteor. Soc. Jpn. Ser. II 82(6): 1599-1628.

$\mathrm{Xu}$ YL, Zhang Y, Lin E, Lin W, Dong W, Jones R, Hassell D, Wilson S. 2006. Analyses on the climate change responses over China under SRES B2 scenario using PRECIS. Chinese Sci. Bull. 51(18): 2260-2267.

Yang X, Liu Z, Chen F. 2010. The possible effects of global warming on cropping systems in China I. The possible effects of climate warming on Northern limits of cropping systems and crop yields in China. Scientia Agricultura Sinica 43(2): 329-336 (in Chinese).

Yao F, Qin P, Zhang J, Lin E, Boken V. 2011. Uncertainties in assessing the effect of climate change on agriculture using model simulation and uncertainty processing methods. Chinese Sci. Bull. 56(8): 729-737

Zhai P, Pan X. 2003. Trends in temperature extremes during 1951-1999 in China. Geophys. Res. Lett. 30(17): 1913, DOI: 10.1029/2003GL018004.

Zhang B, Zhu G. 1959. Climate Regionalization in China (first draft). Science Press: Beijing; 1-297 (in Chinese).

Zheng JY, Yin YH, Li BY. 2010. A New Scheme for climate regionalization in China. Acta Geographica Sinica 65(1): 3-12 (in Chinese).

Zhou T, Yu R. 2006. Twentieth-century surface air temperature over China and the globe simulated by coupled climate models. J. Climate 19(22): $5843-5858$. 